\title{
The Expression of miR-141 and mRNA PTEN with Cisplatin Therapy on NPC
}

\section{Widyandani Sasikirana ${ }^{1}$, Muhammad Radifar ${ }^{1}$, Cita Herawati ${ }^{2}$, Agus Surono ${ }^{3}$, Indwiani Astuti ${ }^{3}$, Teguh Aryandono $^{3}$, and Sofia Mubarika Haryana ${ }^{3}$}

1Departement of Biotechnology, Graduate School, Universitas Gadjah Mada, Jl. Teknika Utara, Yogyakarta, 55281, Indonesia

${ }^{2}$ Dharmais Cancer Hospital, JI. Let. Jend. S. Parman Kav. 84-86, Jakarta, 11420, Indonesia

${ }^{3}$ Post Graduate Program, Faculty of Medicine, Public Health and Nursing, Universitas Gadjah Mada, Jl. Farmako Utara, Yogyakarta, 55281, Indonesia

\section{Abstract}

The incidence of NPC in Yogyakarta province is $6.2 / 100000$ population and the tendency is increasing in the younger population. It has been known that drugs resistance also issues in NPC therapy. Cisplatin is drugs of choice that used in NPC therapy, besides miR-141 and mRNA PTEN are also had a role in chemotherapy

Corresponding Author: Sofia Mubarika Haryana sofia.mubarika@gmail.com

Received: 10 November 2018 Accepted: 6 January 2019 Published: 10 March 2019

Publishing services provided by Knowledge E

(c) Widyandani Sasikirana et al. This article is distributed under the terms of the Creative Commons Attribution License, which permits unrestricted use and redistribution provided that the original author and source are credited.

Selection and Peer-review under the responsibility of the UASC Life Sciences 2016 Conference Committee. resistance in some of cancer. We conducted the examination of the expression of miR-141 from blood plasma pre and post-therapy patient and blood plasma in healthy control. The sample collected from whole blood and then plasma separation. RNA extracted using RNA Isolation Kit miRCURY-Biofluid, synthesis cDNA with cDNA Synthesis kit. mRNA analysis with KAPA SYBR ${ }^{\circledR}$ FAST One-Step qRT-PCR Kit then detected by qRT-PCR. Data analysis with comparative analysis and statistical analysis. MiR-141 showed upregulation by 1.49 (p-value: 0.075) and mRNA PTEN showed downregulation by 0.65 ( $p$-value: 0.323 ) in patients NPC compared to healthy control and there is a relationship between miR-141 and mRNA PTEN ( $p$-value:0.001). The expression levels of miR-141 in patients pre- and post-therapy experience down-regulated (fold change:0.61, two-tailed t-test: 0.09) and mRNA expression levels of PTEN experience down-regulated (fold change:0.5, t-test two-tailed:0.09). The level expression of mRNA PTEN is still down-regulated through the expression of miR-141 is up-regulated indicated that the possibility of drugs resistance in therapy with cisplatin. Then, miR-141 is one of the important factors in cisplatin drugs resistance with inhibition of mRNA PTEN.

Keywords: miR-141, mRNA PTEN, Cisplatin, Drugs resistance, NPC.

\section{Introduction}

NPC is happening by insertion of EBV-DNA viruses. EBV infects B lymphocyte by expressed the LMP1 (oncogene) to increase B-cell proliferation by making a similar signal to activated B-cell by upper cell molecule B-cell, CD40. In another hand, LMP-1 
[1]. To achieve long-term in vivo, the EBV express the latent gene which causes latent infection [2].

The drugs of choice in NPC therapy was cisplatin, an inorganic metal drugs as an alkylating agent. As an alkylating agent, it works by inhibiting cross-linking in the N7 alkyl group of guanines and makes uncoil strand [3]. The issue of drugs resistance in cancer therapy have been investigated after cisplatin therapy [4]. Molecular mechanism of cisplatin resistance has been investigated caused by a kinase, such as Akt and YAP1. Alteration of the kinase expressions has been influenced by the expression of a tumor suppressor gene. MicroRNA, the single-strand non-coding RNA has been worked in post-transcriptional mechanism and could be suppressed the expression of tumor suppressor gene [5].

miR-141 have been investigated in NPC proliferation cells by downregulated PTEN, a tumor suppressor gene as an antagonist in the AKT/PI3K pathway [6]. miR-141 have been investigated a role in resistance to cisplatin in esophageal squamous cell carcinoma by targeting YAP1 [7]. In ovarian cancer have been investigated the role of miR-141 in cisplatin resistance by targeting KEAP1 [8]. Induction of NPC in Akt/FoxO pathway is known to lead to their resistance to cisplatin [9].

A research study in NPC cells has investigated the role of miR-141 and mRNA PTEN in NPC pathogenesis. miR-141 has been investigated as oncomiR and mRNA PTEN was targetted [6]. In order to support the noninvasive biomarker agent in drugs resistance, research on miR-141 and mRNA PTEN expression was conducted in blood plasma of NPC patients. At the same time, inhibition of EBV-miR to mRNA PTEN also done to investigate the miRNA-miRNA interaction by in silico study.

\section{Materials and Methods}

\subsection{Sample collections}

Sample collections used was some blood patients with NPC (pre and post therapy) and plasma of normal people from Dharmais Cancer Hospital and diagnoses of NPC has been done by Cita Herawati. All sample experiments were approved by the ethical committee of Faculty of Medicine, Public Health and Nursing, Universitas Gadjah Mada.

\subsection{Material}




\subsubsection{Equipment}

Micropipet tube, microRNA mini spin column BF (Exiqon), vortex, centrifuge, spin down, thermal cyder Biorad c1000, qRT-PCR Biorad.

\subsubsection{Material}

Alcohol 70 \%, isopropanol p.a, rDNAse, miRCURY RNA isolation kit-Biofluid Exiqon (Lysis solution BF, Protein precipitation solution BF, Wash solution 1 dan 2 BF, RNAse free water), kit universal cDNA synthesis kit II, 8-64 rxns (cat no. 2-33-1, exiqon), 5 times of reaction buffer, nuclease free water, spike in (Sp6), enzyme mix, ice pack. miRCURY LNA Universal RT micro RNA PCR, LNA PCR Primer Set, hsa-miR-141-3p UAACACUGUCUGGUAAAGAUG

For mRNA: KAPA SYBR ${ }^{\circledR}$ FAST One-Step qRT-PCR Kit Universal (KAPA SYBR FAST qPCR master mix, ROX Reference Dye High, ROX Reference Dye Low, dUTP, KAPA RT mix), primer set mRNA PTEN (forward: GGGTCTGAGTCGCCTGTCA, reverse: CCGTGTTGGAGGCAGTAGAAG), primer beta-actin (forward: GGGAATTCAAAACTGGAACGGTGAAGG, reserve: GGAAGCTTATCAAAGTCCTCGGCCACA). The primer of mRNA PTEN was available from Vinciguerra, et al.[10].

\subsection{Methods}

\subsubsection{Plasma isolation}

Blood sample in vacutainer EDTA has been centrifuged at $1500 \mathrm{rad} \cdot \mathrm{s}^{-1}$ in $10 \mathrm{~min}$ and collect the plasma. Total RNA from blood plasma was extracted using the miRCURY RNA Isolation Kit-Biofluid (Cat No. 300112, Exiqon). Complementary DNA was prepared from DNAse-treated RNA samples with Universal cDNA Synthesis kit II, 8-64 rxns (Cat. No. 203301, Exiqon). Quantitative PCR was performed on a StepOnePlus real-time PCR system (Applied Biosystems) using Exilent SYBR Green master mix (Cat No. 203402, Exiqon). mRNA PTEN was detected using KAPA SYBR ${ }^{\circledR}$ FAST One-Step qRT-PCR KIT Universal, All instructions according to the manufacturer's instructions. 


\subsubsection{Quantitative real-time PCR}

Total RNA from blood plasma was extracted using the miRCURY RNA Isolation KitBiofluid (Cat No. 300112, Exiqon). Complementary DNA was prepared from DNAsetreated RNA samples with Universal cDNA Synthesis kit II, 8-64 rxns (Cat. No. 203301, Exiqon). Quantitative PCR was performed on a StepOnePlus real-time PCR system (Applied Biosystems) using Excellent SYBR Green master mix (Cat No. 203402, Exiqon). mRNA PTEN was detected using KAPA SYBR ${ }^{\circledR}$ FAST One-Step qRT-PCR KIT Universal

\subsubsection{Data analysis}

Data have been analyzed with comparative quantitative, $2 \Delta \Delta \mathrm{Ct}$ method, using miR-16 and beta-actin $\mathrm{Ct}$ to reference gene.

\section{Results}

Table 1 describes the expression of miR-141 and mRNA PTEN in the sample. The expression of miR-141 has been upregulated after cisplatin therapy, but the expression of mRNA PTEN have been downregulated after therapy. Its indicated that the therapy was not responded.

TABLE 1: The expression of miR-141 and mRNA PTEN in blood plasma sample by Fold Change $(2 \Delta \Delta \mathrm{Ct}$ method).

Sample
miR-141
mRNA PTEN

\begin{tabular}{|c|}
\hline Before treatment \\
\hline 1.49 \\
0.69
\end{tabular}

\begin{tabular}{|c|}
\hline After treatment \\
0.61 \\
0.5
\end{tabular}

NPC happen because of EBV genome insertion. Then we conducted interaction between EBV-miR with mRNA PTEN by in silico study with Vienna Package Software (Figure 1). The study has been done for investigated the reason of down-regulated of mRNA PTEN after therapy. All of EBV-miR have been targeted mRNA PTEN, which means that its interaction may cause the down-regulated of mRNA PTEN. 

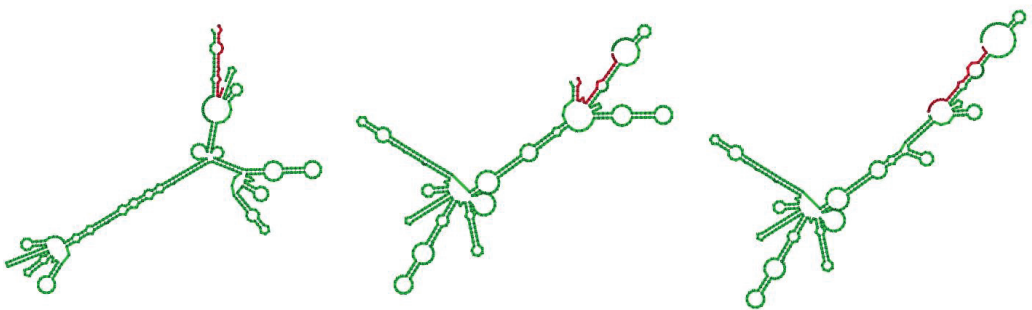

MFE Bartl-5p $=86.50 \mathrm{kcal} \cdot \mathrm{mol}^{-1}$

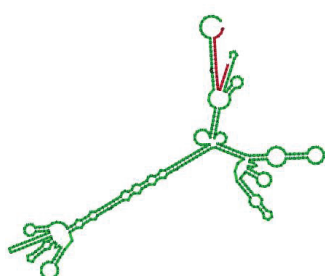

MFE Bart2-5p= $=87.30 \mathrm{kcal} \cdot \mathrm{mol}^{-1}$

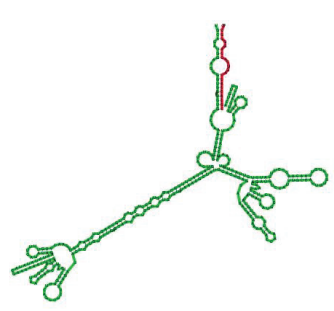

MFE Bart3-3p $=85.80 \mathrm{kcal} \cdot \mathrm{mol}^{-1}$

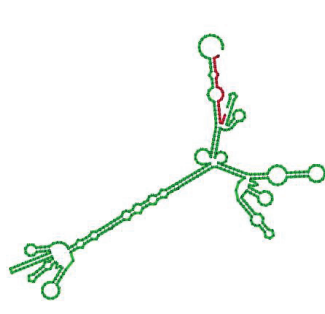

MFE Bart3-5p $=84.20 \mathrm{kcal} \cdot \mathrm{mol}^{-}$
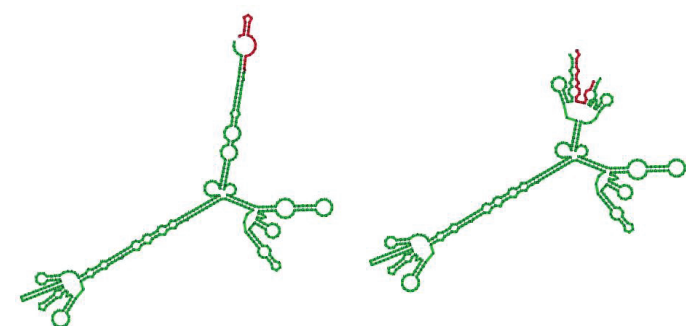

MFE Bart4-3p $=84.40 \mathrm{kcal} \cdot \mathrm{mol}^{-1}$
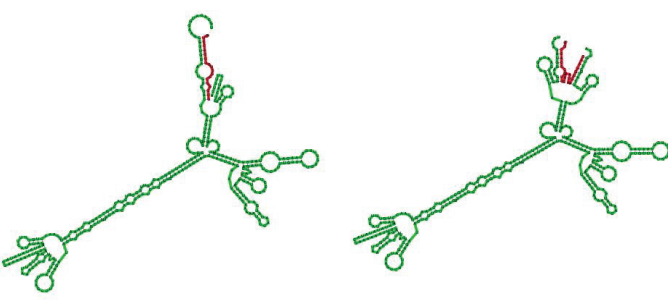

MFE Bart5-5p= $=89.40 \mathrm{kcal} \cdot \mathrm{mol}^{-1}$

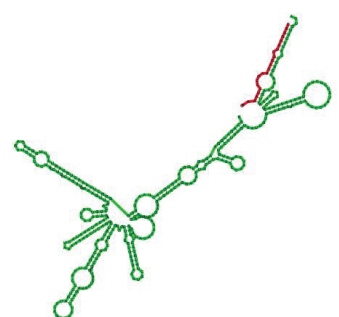

MFE Bart6-3p $=89.90 \mathrm{kcal} \cdot \mathrm{mol}^{-1}$

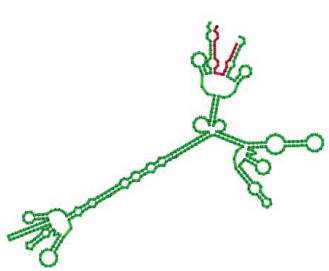

MFE Bart6-5p=-86.60 kcal $\cdot \mathrm{mol}^{-1}$

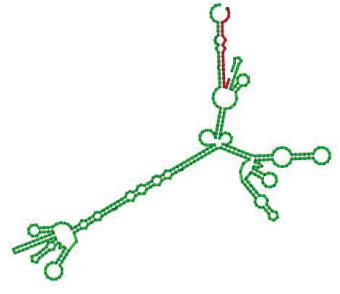

MFE Bart7-3p $=85.80 \mathrm{kcal} \cdot \mathrm{mol}^{-1}$

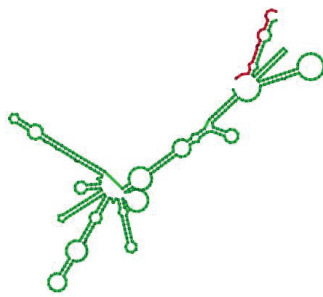

MFE Bart7-5p $=82.40 \mathrm{kcal} \cdot \mathrm{mol}^{-1}$

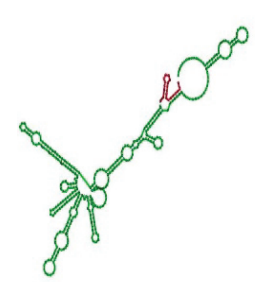

MFE Bart8-3p $=87.70 \mathrm{kcal} \cdot \mathrm{mol}^{-1}$

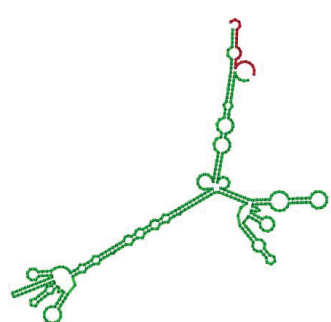

MFE Bart8-5p $=82.90 \mathrm{kcal} \cdot \mathrm{mol}^{-1}$ 


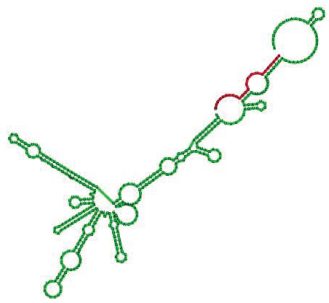

MFE Bart9-3p $=85.00 \mathrm{kcal} \cdot \mathrm{mol}^{-1}$

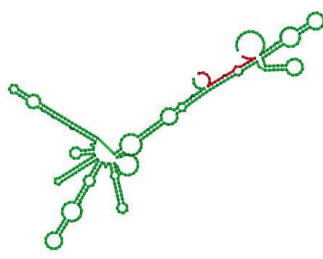

MFE Bart9-5p $=-86.70 \mathrm{kcal} \cdot \mathrm{mol}^{-1}$

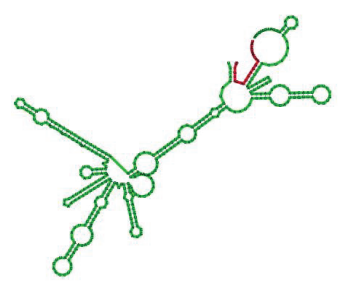

MFE Bart10-3p $=85.60 \mathrm{kcal} \cdot \mathrm{mol}^{-1}$

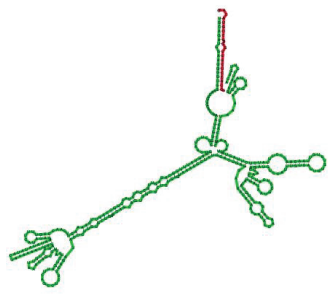

MFE Bart $10-5 \mathrm{p}=95.90 \mathrm{kcal} \cdot \mathrm{mol}^{-1}$
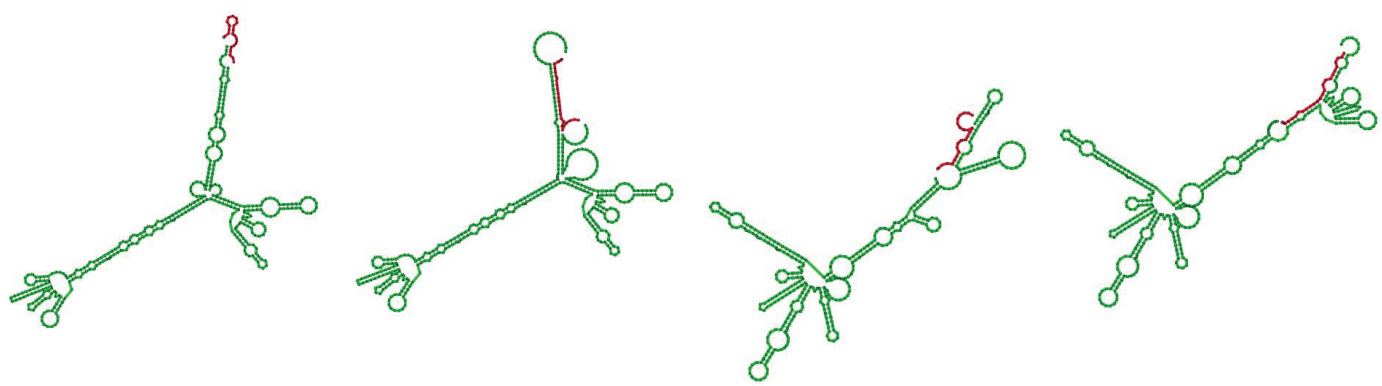

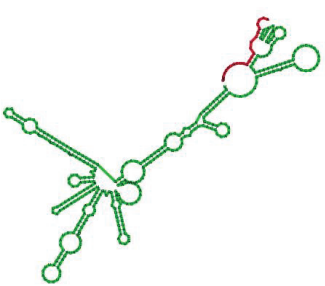

MFE Bart13-5p $=82.90 \mathrm{kcal} \cdot \mathrm{mol}^{-1}$

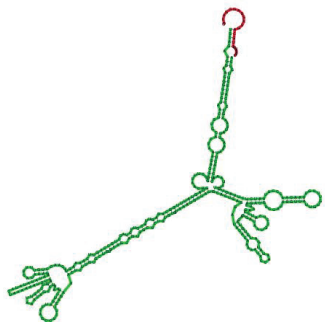

MFE Bart14-3p $=86.00 \mathrm{kcal} \cdot \mathrm{mol}^{-1}$

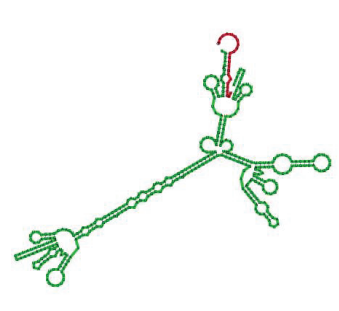

MFE Bart14-5p= $=86.30 \mathrm{kcal} \cdot \mathrm{mol}^{-1}$

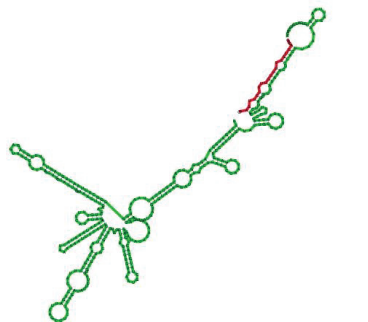

MFE Bart15 $=84.50 \mathrm{kcal} \cdot \mathrm{mol}^{-}$
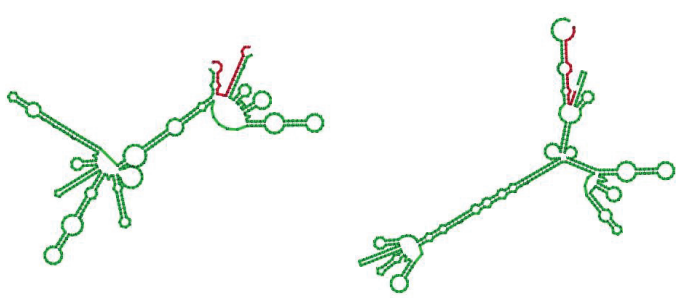

MFE Bart17-3p $=87.00 \mathrm{kcal} \cdot \mathrm{mol}^{-1}$

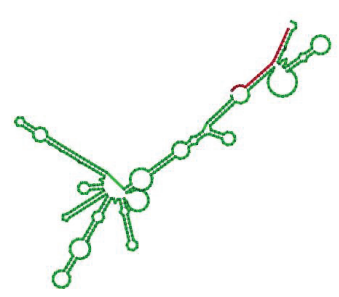

MFE Bart17-5p $=87.70 \mathrm{kcal} \cdot \mathrm{mol}^{-1}$

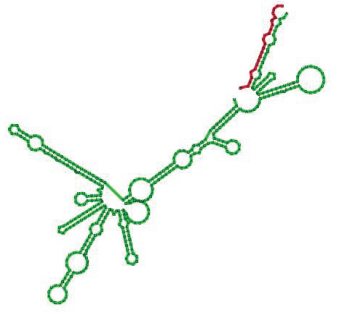

MFE Bart $18-3 \mathrm{p}=86.00 \mathrm{kcal} \cdot \mathrm{mol}^{-}$

\section{Discussion}

miR-141 have been investigated as oncomir by down-regulated mRNA PTEN in blood plasma NPC. PTEN plays a role in conducting dephosphorylation of PIP3 into PIP2 on 

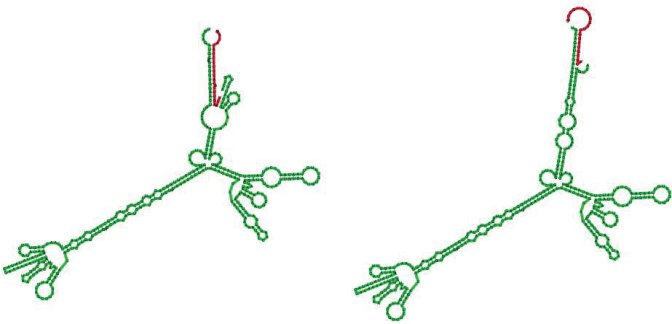

MFE Bart $19-3 \mathrm{p}=85.80 \mathrm{kcal} \cdot \mathrm{mol}^{-1}$

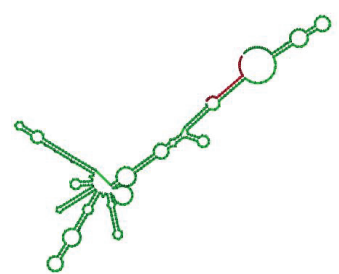

MFE Bart19-5p=-85.30 kcal $\cdot \mathrm{mol}^{-1}$

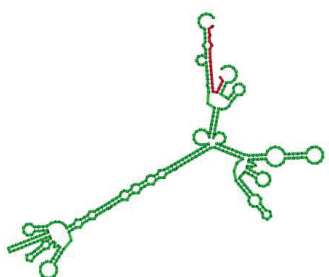

MFE Bart $20-3 \mathrm{p}=87.60 \mathrm{kcal} \cdot \mathrm{mol}^{-}$

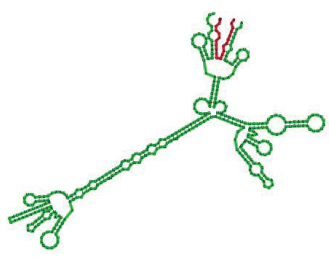

MFE Bart20-5p= $87.10 \mathrm{kcal} \cdot \mathrm{mol}^{-1}$

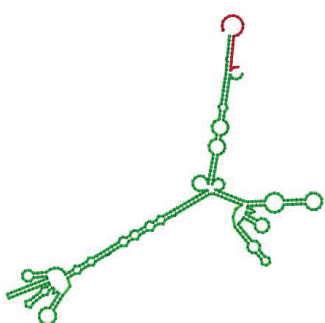

MFE Bhrfl-2-3p= $=84.50 \mathrm{kcal} \cdot \mathrm{mol}^{-1}$

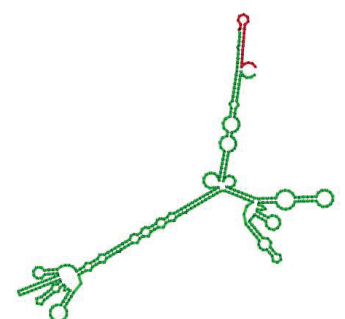

MFE Bhrfl-2-5p= $=85.10 \mathrm{kcal} \cdot \mathrm{mol}^{-1}$

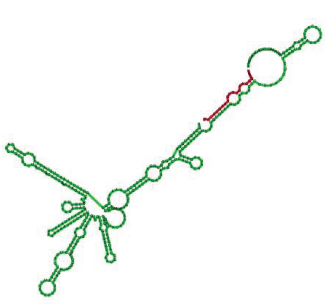

MFE Bhrfl-3=-89.00 $\mathrm{kcal} \cdot \mathrm{mol}^{-1}$

Figure 1: mRNA PTEN-EBV-miR interaction by Vienna Package Software (Green: PTEN. Red: EBV-miR). The strongest interaction was seen in PTEN-EBV-Bart10-5p (MFE $=-95.90 \mathrm{kcal} \cdot \mathrm{mol}^{-1}$ ).

Akt phosphorylation of PI3K pathway [9]. However, miR-141 as oncomir can inhibit the expression of PTEN in post-transcriptional processes. The expression of oncomir also decreased after drugs therapy, which it can increase the expression of mRNA targetted. However, the expression of mRNA PTEN was upregulated after therapy although the expression of miR-141 was down-regulated. It has meant that the therapy was not responded and there might be cisplatin resistance.

In cellular respond, cisplatin can be interacted with secondary thiols, like glutathione and metallothionein. Glutathione-cisplatin conjugated exit from the cell by ATPdependent pump. After cisplatin interacted with DNA, it will inhibit proliferation by activated DNA damage. Kinase such as Akt, PKC, and ERK is also involved in the regulation of cell death that induced by cisplatin. miR-214 was promoted cisplatin resistance by downregulating PTEN and Akt [11]. miR-141 might be promoted cisplatin resistance by downregulating PTEN and Akt activated similar as miR-214.

The inhibition in mRNA PTEN by another oncomir, like EBV-miR, makes mRNA PTEN down-regulated and not responded to cisplatin therapy. miRNA-miRNA interaction may be potential on complex network regulation of biological processed [12]. Another miRNA can influence any miRNA by regulated their targeted and modulated their activity [13]. 


\section{Conclusions}

miR-141 is one of the important factors in cisplatin drugs resistance through inhibition of mRNA PTEN and Akt activated signaling. mRNA PTEN in NPC might be bound to EBVmiR that makes mRNA PTEN down-regulated and not responded to cisplatin therapy

\section{Acknowledgments}

Authors thank the Ministry of Research, Technology, and Higher Education of the Republic of Indonesia for research funding awarded Dharmais Cancer Hospital [Grant Number: UGM/219/LPPM/2015] for providing the samples and also Genomirs Research Team.

\section{References}

[1] Robbins SL, Kumar V. Buku ajar patologi I. [Basic pathology part I]. Penerbit Buku Kedokteran EGC. Jakarta; 2012. p.225. [in Bahasa Indonesia]. http://kink.onesearch. id/Record/IOS3737.SULUT000000000001352

[2] Young LS, Dawson CW. Eipstein-Barr virus and nasopharyngeal carcinoma. Chin J Cancer 2014; 33(12):581. https://www.ncbi.nIm.nih.gov/pmc/articles/PMC4308653/

[3] Gan GS. Farmakologi dan terapi edisi 5. [Pharmacology and therapy $5^{\text {th }} \mathrm{Ed}$ ] Departemen Farmakologi dan Terapeutik, FK UI; 2009. p. 746. [in Bahasa Indonesia]. http://kink.onesearch.id/Record/IOS8.DEPKES-OAl:3316

[4] Basu A, Krishnamurthy S. Cellular responses to cisplatin-induced DNA damage. [Review Article]. Journal of Nucleic Acid. 2010;2010:1-16. https://www.hindawi.com/ journals/jna/2010/201367/

[5] Svoronos AA, Engelman DM, Slack FJ. OncomiR or tumor suppressor? The duplicity of microRNAs in cancer. Cancer Res. 2016;76(13):3666. https://www.ncbi.nlm.nih.gov/ pmc/articles/PMC4930690/

[6] Zhang L, Deng T, Li X, Liu H, Zhou H, Ma J, Wu M, et al. MicroRNA-141 is involved in a nasopharyngeal carcinoma related genes network. Carcinogenesis 2010;31(4):564. https://www.ncbi.nlm.nih.gov/pubmed/20053927

[7] Imanaka Y, Tsuchiya S, Sato F, Shimada Y, Shimizu K, Tsujimoto G. MicroRNA141 confers resistance to cisplatin-induced apoptosis by targeting YAP1 in human esophageal squamous cell carcinoma. 2011;56(4):270https://www.ncbi.nlm.nih.gov/ pubmed/21289630 
[8] Jaarsveld MT, Helleman J, Boersma AW, van Kuijk PF, van ljcken WF, Despierre E, Vergote I, et al. miR-141 regulates KEAP1 and modulates cisplatin sensitivity in ovarian cancer cells. Oncogene. 2013; 32(36):4284. https://www.ncbi.nIm.nih.gov/pubmed/ 23045278.

[9] Ching-Chuan K, Jang-Yang C, Yen-Ting C, Hung-Jie W, Wan-Shu L, Huang-Hui C, Chi-Yen $C$ et al. Activation of Akt/FoxO axis confers resistance to cisplatin in human nasopharyngeal carcinomas. In: Proceedings of the 102nd Annual Meeting of the American Association for Cancer Research; 2011 Apr 2-6; Orlando, FL. Philadelphia (PA): AACR; Cancer Res 2011;71(8):1701. http://cancerres.aacrjournals.org/content/71/ 8_Supplement/1701

[10] Vinciguerra M, Fabio C, Marion P, Sebastian C, Roberto M, Roberto B, Michelangelo F. Unsaturated fatty acids promote hepatoma proliferation and progression through downregulation of the tumor suppressor PTEN. Journal of Hepatology 2009;50:1139. https://www.ncbi.nlm.nih.gov/pubmed/19398230

[11] Chalhoub N, Baker SJ. PTEN and the PI3-Kinase Pathway in Cancer. Annu Rev Pathol. 2009;4:127-150. https://www.ncbi.nlm.nih.gov/pubmed/18767981

[12] Guo L, Su B, Wu Q, Yang S, Chen F. miRNA-miRNA interaction implicates for potential mutual regulatory pattern. Gene 2012:511(2):194. https://doi.org/10.1016/j.gene.2012. 09.066 .

[13] Alshalalfa M. MicroRNA response element-mediated miRNA-miRNA interactions in Prostate Cancer. Hindawi Publishing Corporation. Advances in Bioinformatics 2012: 2012:1-10 https://www.ncbi.nlm.nih.gov/pubmed/23193399 